\title{
Strontium incorporation into calcified structures: separating the effects of ambient water concentration and exposure time
}

\author{
Travis S. Elsdon*, Bronwyn M. Gillanders \\ Southern Seas Ecology Laboratories, Darling Building DP 418, School of Earth and Environmental Science, \\ The University of Adelaide, Adelaide, South Australia 5005, Australia
}

\begin{abstract}
Chemical elements within calcified structures of organisms such as fish, corals, bivalves, gastropods and foraminiferal shells can provide a record of the environmental characteristics at the time of calcification. To predict accurately the environmental characteristics at the time of calcification, it is important to understand the influence of exposure time on elemental incorporation. We examined the effect of enhanced ambient strontium:calcium (Sr:Ca) $(2 \times$ and $4 \times$ ambient concentrations) and different periods of exposure $(2,4,8,16$ and $32 \mathrm{~d})$ on Sr:Ca uptake and incorporation into fish otoliths of the black bream Acanthopagrus butcheri (family: Sparidae). Sr:Ca ratios (hereafter referred to as concentrations) in bream otoliths increased with increasing ambient concentrations, with the amount of Sr:Ca incorporated into otoliths being positively affected by the period of exposure. Saturation of $\mathrm{Sr}$ :Ca in otoliths occurred after $20 \mathrm{~d}$ of exposure. Importantly, by measuring multiple variables of elemental uptake and incorporation, the relative effect of enhanced concentration and exposure time can be separated, which to date has not been possible. This research will allow for greater accuracy when interpreting environmental histories of fish.
\end{abstract}

KEY WORDS: Trace element - Strontium $\cdot$ Laser ablation ICP-MS $\cdot$ Uptake $\cdot$ Exposure $\cdot$ Transects · Migration

\section{INTRODUCTION}

Elements within calcified structures of fish, corals, molluscs and foraminiferal shells have been used to reconstruct environmental histories of extant and extinct species (e.g. Lea \& Spero 1994, Brown \& Luoma 1995, Shen et al. 1996, Alibert \& McCulloch 1997, Rosenthal et al. 1997, Tzeng et al. 1997, Secor et al. 2001, Ikeda et al. 2003, Zacherl et al. 2003). Environmental histories commonly described include water temperature (Alibert \& McCulloch 1997), salinity (Kafemann et al. 2000) and ambient elemental concentrations (Secor et al. 2001), all of which can reconstruct past climatic conditions. For example, past environments inhabited by Porites corals have been inferred from Sr concentrations, where temperature has been shown to affect Sr incorporation (Alibert \& McCulloch 1997).
Reconstructions of environmental histories commonly use equations that are derived from either manipulative laboratory experiments, using controlled conditions (e.g. Elsdon \& Gillanders 2003b), or by measurements during field collection (e.g. Shen et al. 1998). Such equations describe the effects of environmental variables on the elemental concentrations within calcified structures, without accounting for the amount of time organisms are exposed to environmental variables. Many calcified structures, such as fish otoliths (earbones) and spines, are not in direct contact with the surrounding seawater, with physiological (cellular) and physical boundaries existing (concentration gradients in organisms). Elements must pass through these boundaries before being incorporated into the matrix of calcified structures; therefore, it is plausible that changes in environmental variables would not 
result in instantaneous changes in elements within calcified structures. Consequently, the rate at which elements are incorporated into calcified structures would affect the interpretation of environmental histories, both spatially and temporally.

The time required for elements to be incorporated into calcified structures is largely unknown, although there have been several attempts to examine the effect of exposure time to enhanced elemental concentrations on the uptake and incorporation of elements in fish otoliths, spines and vertebrae (Snyder et al. 1992, Ennevor \& Beames 1993, Brown \& Harris 1995, Pollard et al. 1999). Due to technical constraints, all of these experiments analysed whole calcified structures using solution-based techniques (e.g. whole otolith), and, in doing so, the derived elemental signatures were a mixture over the entire chronology of the structure. As reconstructions of environmental histories require high resolution of elemental concentrations, sample analysis requires the use of fine-scale micromilling or laser instruments (Elsdon \& Gillanders 2003a). Nevertheless, experiments using solution-based techniques have shown that an increased period of exposure to environmental variables results in enhanced concentrations of elements being incorporated into calcified structures of fish (e.g. Pollard et al. 1999). Further experiments using more modern sample analysis are needed to assess the effects of exposure time on elemental incorporation; these experiments will provide more accurate interpretations of environmental histories of organisms.

Sr in otoliths is largely derived from the surrounding water (Milton \& Chenery 2001), with minimal dietary influence. Numerous experiments have related changes in ambient $\mathrm{Sr}$ to changes in calcified structures of fish otoliths (e.g. Schroder et al. 1995, Bath et al. 2000, Elsdon \& Gillanders 2003b), fish scales (e.g. Mugiya et al. 1991, Wells et al. 2000) and foraminiferal shells (e.g. Lea \& Spero 1992). For Sr, a strong positive relationship exists between ambient and otolith concentrations. Although the relationship between the ambient elements and that of the calcified structure remains near linear for a large number of organisms (such as corals and foraminiferal shells, Lea \& Spero 1992, Ferris-Pagès et al. 2002), otoliths display elemental discrimination, due to environmental and biological factors affecting elemental incorporation (such as temperature, Bath et al. 2000, Elsdon \& Gillanders 2003b).

Reconstructions of the environmental histories of fish using the elements in calcified structures have been based on fine-scale analysis, using either laser or micromilling techniques (e.g. Kafemann et al. 2000), where peaks in the absolute elemental concentration are related to environmental variables (e.g. Tzeng et al. 2002). Previously, Elsdon \& Gillanders (2003a) have shown that the scale of otolith analysis, fine $30 \mu \mathrm{m}$ transects versus large $100 \mu \mathrm{m}$ spot sampling, affects the detected elemental concentrations in laboratoryreared fish. Thus, fine-scale analyses allow for greater and more accurate resolution of environmental histories. The analysis of transects across structures results in a continuous elemental record that can be interpreted using several variables (e.g. height, distance, slope and areas of peaks and troughs; see Fig. 1); each variable relates to a function of elemental uptake and incorporation. Fine-scale transect analysis can be used to assess the effect of exposure time to changes in environmental variables on the elemental incorporation into otoliths. The resulting data should aid the interpretation of environmental histories of fish.

The lack of information regarding the influence of exposure time on elemental uptake into calcified structures is a severe inhibitor in determining environmental histories of organisms. In the present study, we tested the hypothesis that the effect of exposure to enhanced concentrations of ambient $\mathrm{Sr}$ on the concentration of otolith $\mathrm{Sr}$ is significantly affected by the exposure time. Specifically, juvenile black bream Acanthopagrus butcheri were exposed to enhanced concentrations of $\mathrm{Sr}$, for a range of time periods (from 2 to $32 \mathrm{~d}$ ), in controlled laboratory conditions. The relative and interactive effects of concentration and exposure time on $\mathrm{Sr}$ concentration in otoliths were then documented.

\section{MATERIALS AND METHODS}

Experimental design. Juvenile black bream Acanthopagrus butcheri of approximately $25 \mathrm{~mm}$ total length were obtained from a hatchery and held in replicate $250 \mathrm{l}$ fibreglass holding tanks containing seawater $(33 \%)$ of ambient elemental concentration at $20^{\circ} \mathrm{C}$. Tanks were supplied with filtration and aeration. The fish were bred from a common brood stock to reduce genetic variability; the influence of genetics on otolith chemistry is unknown. Fish were held in the holding tanks for $10 \mathrm{~d}$ before being exposed to experimental conditions. All seawater used during the rearing process was collected weekly from the South Australian Research and Development Institute, Aquatic Sciences Division, and was held in a covered and aerated $2000 \mathrm{l}$ indoor tank. Commercial fish food was used during the experiments. Light was provided from fluorescent tubes on a $12 \mathrm{~h}$ day: $12 \mathrm{~h}$ night cycle, in a constant-temperature room $\left(20^{\circ} \mathrm{C}\right)$.

Black bream otoliths were marked with alizarin complexone (36 ppm) to enable old growth to be distinguished from new growth, which was laid down under experimental conditions. After the initial acclimatisa- 
tion period of $10 \mathrm{~d}$ in 1 of 2 holding tanks, fish were randomly assigned to experimental treatments at densities of 10 to 14 fish per tank. Each tank consisted of a 401 high-density polyethylene tub supplied with aeration and covered with a clear Plexiglas lid to minimise evaporative loss that may change the water chemistry.

The experiment involved manipulating both the concentration of $\mathrm{Sr}$ in the rearing water and the time of exposure to enhanced $\mathrm{Sr}$ in an orthogonal 2-way design, to test the relative and interactive effects of these factors on otolith Sr. Treatments consisted of all possible combinations of Sr spiking $(2 \times$ and $4 \times)$ and times of exposure $(2,4,8,16$ and $32 \mathrm{~d})$. At the start of the experiment, fish were transferred from the holding tanks to experimental tanks and held at an enhanced Sr concentration for the prescribed time period, after which all water was changed back to ambient strontium concentrations (referred to as post-spiking) and held constant until the experiment was terminated (32 d). For each treatment, duplicate tanks were used to assess variability in both the elemental composition of the water and otoliths. A total of 22 tanks were used, 2 of which were control tanks with fish held at ambient Sr concentrations. Sr spiking consisted of the addition of appropriate amounts of standard solution made from $\mathrm{SrCl}_{2} \cdot 6 \mathrm{H}_{2} \mathrm{O}$ mixed with seawater. To maintain water quality, $50 \%$ of the rearing water was siphoned off every second day and replaced; any accumulated detritus on the bottom of tanks was removed daily.

During the rearing period, temperature and salinity were monitored on random days $(n=20)$. Replicate water samples were collected on random days $(n=3$ per tank) to determine the actual concentrations of $\mathrm{Sr}$ and $\mathrm{Ca}$ in the water. After $32 \mathrm{~d}$ the experiment was terminated, at which time all fish were immersed in an ice slurry. The sagittal otoliths were dissected, washed thoroughly, cleaned in Milli-Q water and stored in microcentrifuge tubes. Then, 7 fish from each treatment tank were selected, based on similarities of length, and their otoliths were prepared for elemental analysis.

Elements in otoliths. Otoliths from 7 fish per tank (154 otoliths in total) were embedded in epofix resin that had been spiked with $40 \mathrm{ppm}$ indium to allow for discrimination between the otolith and resin upon analysis. Otoliths were sectioned transversely through the focus (centre section) using a low-speed diamond saw, which was lubricated with Milli-Q water. Sections (approximately $300 \mu \mathrm{m}$ thick) were polished using 30 and $9 \mu \mathrm{m}$ lapping film until they were approximately $200 \mu \mathrm{m}$ thick. Polished sections were fixed to glass slides with epofix resin and allowed to dry, after which time slides were sonicated in Milli-Q water for $5 \mathrm{~min}$ and dried in a plastic laminar flow cabinet. Slides were stored in clean, sealable plastic bags until analysed.
The concentration of $\mathrm{Sr}$ and $\mathrm{Ca}$ in otolith samples was determined using a Merchantek LUV 266 Qswitched Nd: YAG UV laser microprobe, with a pulse rate of $6.00 \mathrm{~Hz}$, energy of $1.0 \mathrm{~mJ}$ and spot size of $30 \mu \mathrm{m}$. The laser ablation station was connected to a Finnigan MAT ELEMENT HR-ICP-MS (High Resolution-Inductively Coupled Plasma-Mass Spectrometer) with gas flow parameters of coolant 14.00, auxiliary 1.55, sample 1.5 and helium $0.36 \mathrm{l} \mathrm{min}^{-1}$. Ablations occurred inside a sealed chamber with the sample gas being extracted to the HR-ICP-MS via a smoothing manifold in the presence of argon and helium gas. The chamber was purged for $20 \mathrm{~s}$ after each ablation, to remove background gas or sample from previous ablations that could contaminate resolved concentrations of elements (Lahaye et al. 1997, Elsdon \& Gillanders 2002). Background concentrations of elements within the chamber were measured before each ablation (for 30 s), to correct sample concentrations. During sample ablations the laser scanned at approximately $1.3 \mu \mathrm{m} \mathrm{s}^{-1}$ across the otolith surface, resulting in a continuous transect across the otolith (Sinclair et al. 1998, Fallon et al. 2002). Otoliths were analysed from the centre to the outside edge, with up to $200 \mu \mathrm{m}$ of otolith material being scanned during each ablation; standard materials were also ablated for a total of $200 \mu \mathrm{m}$. The outside edge of the otoliths and end point of the scans were determined when the indium concentration increased, indicating the ablation of resin and not of otolith matrix.

Otoliths were analysed in several sampling sessions along with blank ablations and 2 reference standards, which allowed for comparisons among sampling sessions. Blank ablations that measured the chamber gases in the absence of any sample were analysed before and after the sampling sessions to determine the detection limits of the machine. A reference standard (National Institute of Standards and Technology, NIST 612) was analysed after every 10 otolith ablations to correct for machine drift (Ludden et al. 1995). The concentration of $\mathrm{Sr}$ in bream otoliths was corrected, by adjusting data, using a fish otolith standard (a $32 \mathrm{~mm}$ pressed powdered disk of finely ground otolith similar to that described by Fallon et al. 1999 for coral). The otolith standard was analysed at the beginning and end of each sample session. The analytical accuracy was determined from the concentrations of the NIST standards, and was averaged across all samples; accuracy was $100 \%$ for $\mathrm{Ca}^{44}$ and $99 \%$ for $\mathrm{Sr}^{88}$. Detection limits determined from blank ablations were $1.40 \mu \mathrm{g}$ $\mathrm{g}^{-1}(\mathrm{Ca})$ and $0.66 \mu \mathrm{g} \mathrm{g}^{-1}(\mathrm{Sr})$, with all otolith values being at least 1 order of magnitude greater.

All data reduction was done off-line in spreadsheets following the general methods described by Sinclair et al. (1998). The concentration of Sr:Ca in each transect 
appeared to show noise and required smoothing to determine trends in the data. To reduce the noise along transects, a 9-point running mean was applied to the Sr:Ca ratio. Lower levels (3 and 5 point) of smoothing inadequately reduced noise, and higher levels (11 point) resulted in loss of trends (Sinclair et al. 1998). The Sr:Ca concentrations were then averaged using a 9-point running median to further smooth transects. The results of both the smoothing processes were transects that displayed little noise. Smoothed data were used throughout the rest of the data-reduction process, which included background subtracting, standardising to NIST 612, normalising to calcium (internal standard for ablation yield) and correcting to the otolith standard. Data were standardised to $\mathrm{Ca}$ (e.g. Sr:Ca), as strontium is likely to substitute for calcium in the otoliths of fish (Campana 1999).

Interpretation of $\mathrm{Sr}: \mathrm{Ca}$ concentrations along transects was done by examining several variables of elemental uptake and incorporation (Fig. 1). Height represents the maximum concentration of $\mathrm{Sr}: \mathrm{Ca}$ incorporated into otoliths for each treatment $(\mathrm{Sr}: \mathrm{Ca} \mathrm{mmol}$ $\left.\mathrm{mol}^{-1}\right)$. Distance represents the otolith distance $(\mu \mathrm{m})$ from when fish were exposed to enhanced ambient $\mathrm{Sr}: \mathrm{Ca}$ till when maximum Sr:Ca was incorporated (height). Slope represents the rate of elemental uptake (as a function of height over distance; $\mathrm{Sr}: \mathrm{Ca}, \mathrm{mmol}$ $\mathrm{mol}^{-1} \mu \mathrm{m}^{-1}$ ). Area represents the total Sr:Ca incorporated into otoliths (as a function of the area under transect curves; $\mathrm{Sr}: \mathrm{Ca}, \mathrm{mmol} \mathrm{mol}^{2}$ ). Fig. 1 provides a schematic representation of each variable.

The concentration of Sr:Ca along the transects was partitioned into several sets of data that were representative of $30 \mu \mathrm{m}$ spot analyses. This was done using

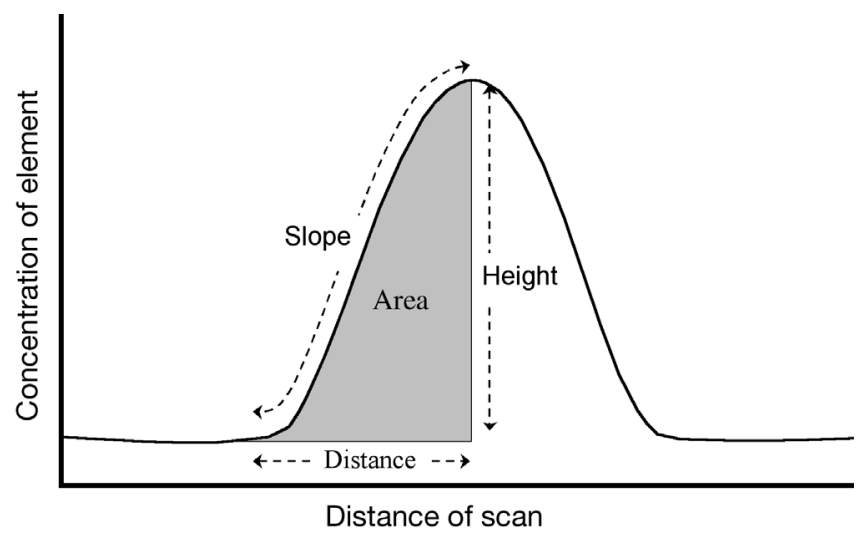

Fig. 1. Measurements (height, distance, slope and area) from transect analysis based on the uptake and incorporation of elements into calcified structures, where height represents the concentration of an element, distance represents the time taken for elemental incorporation, slope represents the rate of elemental incorporation and area is the maximal concentration of an element incorporated into a calcified structure per unit of time blocks of raw elemental counts and standardising them using the methods of Elsdon \& Gillanders (2002), whereby data were background subtracted, standardised to NIST 612 and an otolith standard, and presented as Sr:Ca ratios. The reduction of data into $30 \mu \mathrm{m}$ spot increments allowed comparison between the results of the transect analysis and other forms of otolith analysis, such as those obtained using spot or micromill techniques.

Elements in water. Replicate water samples (three $50 \mathrm{ml}$ samples) were collected on randomly selected days from each of the 2 holding tanks, each treatment tank during the spiked period, and 3 random tanks postspiking. Water samples were collected in polypropylene sample jars, which were acid washed in $10 \%$ nitric acid mixed with Milli-Q water to leach metals. Half $(25 \mathrm{ml})$ of each sample was filtered through a $0.45 \mu \mathrm{m}$ filter and acidified with $500 \mu \mathrm{l}$ of high-grade nitric acid, before being refrigerated (Elsdon \& Gillanders 2002). Samples were further diluted (1:10, sample:deionised water) before being analysed by either ICP-MS or ICP-AES.

Water samples were analysed using a Perkin Elmer 3000 DV ICP-AES (Dual View Inductively Coupled Plasma-Atomic Emission Spectrometer) for the analysis of $\mathrm{Ca}^{44}$ and a Perkin Elmer Elan 6000 DRC ICP-MS (Dynamic Reaction Cell Inductively Coupled PlasmaMass Spectrometer) for the analysis of $\mathrm{Sr}^{88}$. Internal standards of indium (In, $5 \mathrm{ppb}$ ) and lutetium ( $\mathrm{Lu}$, $2 \mathrm{ppb}$ ) were used to correct for drift of the ICP-MS and ICP-AES, respectively. Detection limits displayed as micrograms per litre were $5.0(\mathrm{Ca})$ and $1.0(\mathrm{Sr})$. All sample values were above detection limits. The analytical accuracy of calcium and strontium averaged across all samples was $100 \%(\mathrm{Ca})$ and $87 \%$ (Sr), with a repro-

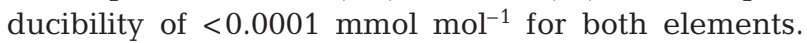
Strontium was standardised to calcium, and was expressed as a ratio (Sr:Ca).

Statistical analysis. The univariate analysis of ambient Sr:Ca concentrations in rearing water proceeded in 3 steps. First, to determine if strontium persisted after the spiked period, the concentration of Sr:Ca in the 2 holding tanks was compared to 2 randomly selected tanks post-spiking. Second, to determine if the spiking of strontium significantly increased strontium in the water, the concentration of $\mathrm{Sr}$ :Ca was compared in 3 randomly selected tanks of the $2 \times$ and $4 \times$ treatments, and post-spiking tanks. The third step tested for the effects of strontium spiking and time of exposure on $\mathrm{Sr}$ :Ca concentration in rearing water. Analyses in the first 2 tests were done using 2-way ANOVAs with 'treatment' as a fixed factor and 'tank' as a random nested factor within treatment. The test for the third step was done using a 3-way ANOVA with 'concentration' and 'time' as fixed factors and 'tank' as a random nested factor within treatments. 
Univariate ANOVAs were also used to determine if temperature and salinity of the rearing water differed among treatments and if the height, distance, slope and area (see Fig. 1) of otolith Sr:Ca transect curves differed among treatment groups. Three-factor ANOVAs treated both 'concentration' and 'time' as fixed factors and 'tank' as a random factor nested within concentrations. Where significant differences were detected (e.g. p $<0.05$ or $p<0.01$ if heterogeneous), means of treatment groups were compared using Student-Newman-Keuls' (SNK) tests, to determine where these differences occurred.

\section{RESULTS}

\section{Water strontium concentrations and rearing conditions}

\section{Effectiveness of spiking}

Post-spiking the $\mathrm{Sr}: \mathrm{Ca}$ concentration in rearing waters showed no sign of elevation from pre-spiked levels (Fig. 2, Table 1a), with a Sr:Ca difference between pre- and post-spiking concentrations of $<0.015 \mathrm{mmol} \mathrm{mol}^{-1}$. This result indicates that Sr was not enhanced in rearing waters after spiking. The concentration of Sr:Ca in spiked water in both $2 \times$ and $4 \times$ treatments was significantly different when compared to post-spiking tanks, indicating that spiking water with $\mathrm{SrCl}_{2} \cdot 6 \mathrm{H}_{2} \mathrm{O}$ resulted in a detectable difference in $\mathrm{Sr}$ :Ca during the experimental period (Fig. 2, Table $1 \mathrm{~b}$ ). The spiking of rearing water to $2 \times$ and $4 \times$ ambient $\mathrm{Sr}: \mathrm{Ca}$ resulted in concentrations of $18.17 \pm$ 0.07 and $32.28 \pm 0.28 \mathrm{mmol} \mathrm{mol}^{-1}$, respectively; the ambient Sr:Ca concentration was $10.31 \pm 0.01 \mathrm{mmol}$

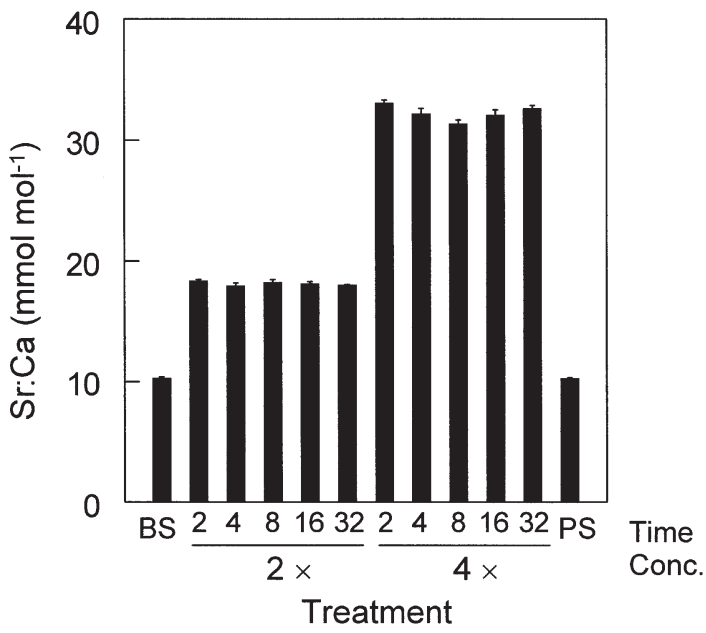

Fig. 2. Concentration of Sr:Ca in the rearing water during the experimental rearing period. BS represents the concentration before elemental spiking, and PS represents that after elemental spiking. Treatments are shown according to concentration (Conc.) and time (in days). Bars represent the mean $+\mathrm{SE}$ of the mean of each treatment

$\mathrm{mol}^{-1}$ (mean $\pm \mathrm{SEM}$ ). Thus, final concentrations of spiking with $\mathrm{SrCl}_{2} \cdot 6 \mathrm{H}_{2} \mathrm{O}$ were not quite $2 \times$ and $4 \times$ that of ambient Sr:Ca concentrations (see also Fig. 2).

The elemental concentrations among treatments were significantly different for concentration, time and the interaction of concentration $\times$ time. The maximum differences in the Sr:Ca concentrations among any 2 tanks of the $2 \times$ and $4 \times$ treatments were 0.412 and $0.984 \mathrm{mmol} \mathrm{mol}^{-1}$, respectively; this suggested that any effect of tank was negligible (see Fig. 2, Table 1c). Importantly, there was no overlap in Sr:Ca concentrations between the $2 \times$ and $4 \times$ treatments, with at least $14.7 \mathrm{mmol} \mathrm{mol}{ }^{-1}$ separating the means of any 2 treat-

Table 1. Analysis of variance comparing (a) the concentration of Sr:Ca in the rearing water before (2 holding tanks) and after ( 2 randomly chosen tanks) the spiking period, (b) the concentration of Sr:Ca in rearing water among $2 \times$ and $4 \times$ spiking and postspiking tanks, and (c) the concentration of Sr:Ca in rearing water among treatments of the full design (Conc.: concentration).

Cochran's test was used to test homogeneity of variance, with all tests being non-significant

\begin{tabular}{|c|c|c|c|c|c|}
\hline & Source of variation & df & MS & $F$ & $\mathrm{p}$ \\
\hline \multirow[t]{3}{*}{ (a) Before vs after spiking } & Treatment & 1 & 0.0008 & 2.53 & 0.2530 \\
\hline & Tank (Treatment) & 2 & 0.0003 & 0.01 & 0.9892 \\
\hline & Residual & 8 & 0.0310 & & \\
\hline \multirow{3}{*}{ (b) Spiked vs post-spiking comparison } & Treatment & 2 & 1180.8708 & 305.72 & 0.0000 \\
\hline & Tank (Treatment) & 6 & 0.1422 & 0.42 & 0.8555 \\
\hline & Residual & 18 & 0.3378 & & \\
\hline \multirow[t]{5}{*}{ (c) Treatment comparison } & Concentration & 1 & 2988.0824 & 791.62 & 0.0000 \\
\hline & Time & 4 & 1.3928 & 5.96 & 0.0102 \\
\hline & Tank (Conc. $\times$ Time) & 10 & 0.2336 & 0.53 & 0.8593 \\
\hline & Conc. $\times$ Time & 4 & 1.2018 & 5.14 & 0.0163 \\
\hline & Residual & 40 & 0.4417 & & \\
\hline
\end{tabular}


$2 \times$ Sr:Ca treatment
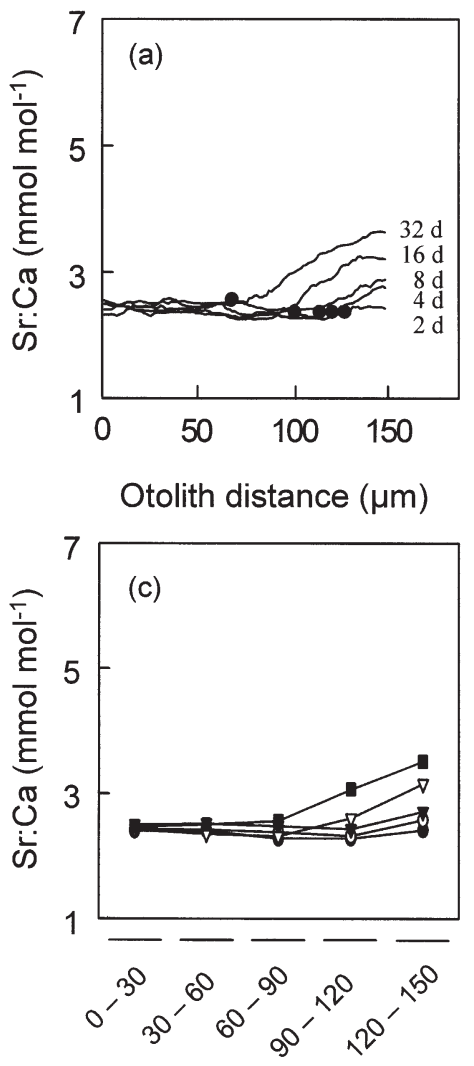

Ablation position $(\mu \mathrm{m})$

\section{$4 \times \mathrm{Sr}: \mathrm{Ca}$ treatment}
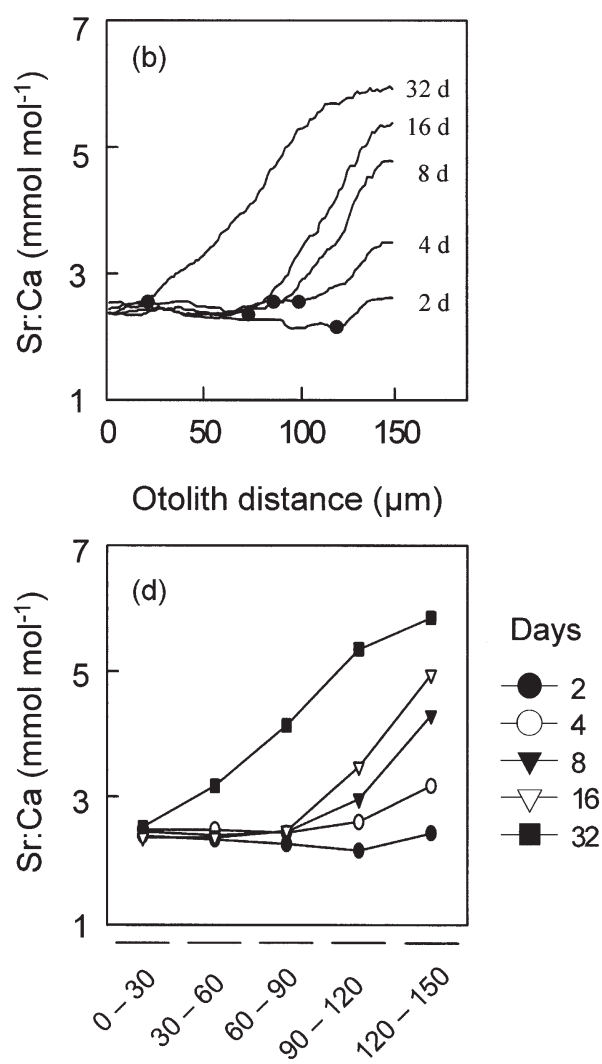

Ablation position $(\mu \mathrm{m})$

Fig. 3. Acanthopagrus butcheri. Strontium concentrations in fish otoliths (Sr:Ca) for 1 representative fish from each treatment analysed using (laser ablation ICP-MS) $30 \mu \mathrm{m}$ transect analysis $(\mathrm{a}, \mathrm{b})$ across the otolith of experimentally reared black bream and corresponding (laser ablation ICP-MS) $30 \mu \mathrm{m}$ spot analysis (c,d) across the same fish otoliths. Individual transects are plotted such that the starting points of exposures do not match up, but the middle peak for each element does. Black circles in Panels a and $b$ represent the approximate time treatments commenced

ments. Thus, the effects of time and the interaction of concentration $\times$ time on ambient $\mathrm{Sr}$ :Ca concentrations were smaller in magnitude compared to the spiking effects.

\section{Temperature and salinity}

Temperature and salinity were not significantly different between treatments of either concentration or time (ANOVA: temperature $\times$ conc.: $F_{1,10}=0.37, \mathrm{p}=$ 0.5554 , time: $F_{4,10}=1.91, \mathrm{p}=0.1862$; salinity $\times$ conc.: $F_{1,10}=0.07, \mathrm{p}=0.7923$, time: $F_{4,10}=0.47, \mathrm{p}=0.7569$ ). The mean temperature and salinity values averaged across all readings were $19.79 \pm 0.01{ }^{\circ} \mathrm{C}$ and $33.00 \pm$ $0.09 \%$, respectively (mean \pm SEM). Tank differences in temperature were detected (ANOVA; temperature $\times$ tank: $\left.F_{10,380}=6.49, \mathrm{p}<0.001\right)$, but, as $<0.45^{\circ} \mathrm{C}$ separated the means of duplicate tanks within each treatment, the effect of temperature differences between tanks was small when compared to the effect of enhanced $\mathrm{Sr}: \mathrm{Ca}$ in water.

\section{Otolith strontium concentrations}

Transect Sr:Ca concentrations

Differences between the $2 \times$ and $4 \times$ concentration treatments can be seen in the height, distance, slope and area of transect curves (Fig. 3a,b). Otolith transects of fish (Acanthopagrus butcheri) reared in $1 \times \mathrm{Sr}$ :Ca concentration (ambient concentration), representing control fish, were stable, and the Sr:Ca concentrations were low (see first $50 \mu \mathrm{m}$ of otolith distance in Fig. 3a for an example). Representative graphs of 1 fish from each treatment using $30 \mu \mathrm{m}$ spot analysis (Fig. 3b,c) conform to the same trends as the transect data, thus showing the generality of these results independent of sampling method andbroadening their application and relevance.

The amount of otolith material laid down during the rearing process was $4.9 \mu \mathrm{m} \mathrm{d}^{-1}$. This growth rate was used to calculate the amount of time taken for $\mathrm{Sr}: \mathrm{Ca}$ to become saturated in otoliths (based on transect distance calculations). The concentration of $\mathrm{Sr}: \mathrm{Ca}$ in otoliths increased with time up to approximately $20 \mathrm{~d}$, when the saturation point was reached (otolith distance of $32 \mathrm{~d}$ treatments [Fig. 4b]/growth of $4.9 \mu \mathrm{m} \mathrm{d}^{-1} \approx 20 \mathrm{~d}$ ) (see Fig. 5 for a graphical representation). Fish held at both $2 \times$ and $4 \times$ ambient elemental concentrations had almost identical saturation times $(2 \times: 18.51 \pm 1.46 \mathrm{~d}, 4 \times: 19.4 \pm 0.80 \mathrm{~d})$, as indicated by the non-significant interactive effect between concentration and time for transect distances (Table 2b). Exposure time of $>20 \mathrm{~d}$ did not result in greater concentrations of $\mathrm{Sr}$ :Ca being incorporated into otoliths, as saturation of $\mathrm{Sr}: \mathrm{Ca}$ in otoliths occurred (see Fig. 5 for an example). Thus, the maximal concentrations displayed in Fig. 4a represent the expected concentrations of $\mathrm{Sr}: \mathrm{Ca}$ in otoliths at different exposure times.

Interactive effects of concentration and exposure time were detected for the height and the slope of 
peaks, while the transect distance and area were non-significant (Fig. 4, Table 2). The interactions detected for both height and slope show a clear increase in concentration of $\mathrm{Sr}$ : Ca with increasing time of exposure, with this effect being greater in the $4 \times$ concentration treatments than in the $2 \times$ treatments (Fig. 4a,c). There was no difference in maximal concentration (height) or rate of uptake (slope) between the $2 \mathrm{~d}$ treatments in $2 \times$ or $4 \times$ concentrations, nor were the 2,4 , or $8 \mathrm{~d}$ treatments within the $2 \times$ concentration significantly different (SNK test, Fig. 4a,c); however, differences in height and slope were detected for all other levels of concentration and time. For distance and area, both concentration and time of exposure were highly significant (Fig. 4b,d, Table 2b,d), with all levels of time being different from one another within each level of concentration (SNK tests, Fig. 4b,d).

\section{Area versus slope}

To distinguish between treatments of concentration and time, a plot of area versus slope was done (Fig. 6). Although fish exposed to elevated $\mathrm{Sr}: \mathrm{Ca}$ for short periods of time remain indistinguishable, those exposed for longer periods (i.e. 8, 16 and 32 d) group out according to both area (total $\mathrm{Sr}: \mathrm{Ca}$ in otoliths) and slope (rate of uptake). Equations of these lines are:

$$
\begin{aligned}
& 2 \times \text { treatments: } y=8426.6 x+0.899 \mathrm{r}^{2}=0.6613 \\
& 4 \times \text { treatments: } y=4485.9 x+16.507 \mathrm{r}^{2}=0.9859
\end{aligned}
$$

where $y$ is area and $x$ is slope. The slopes of all lines were significantly different from 0 slope.

\section{DISCUSSION}

\section{Uptake and incorporation of strontium}

A key finding of the current experiment was a clear increase in otolith Sr:Ca (height) in Acanthopagrus butcheri with increasing water $\mathrm{Sr}$ :Ca from $2 \times$ to $4 \times$ ambient concentrations. Such a relationship between ambient and otolith Sr:Ca has been found in several manipulative experiments (e.g. Bath et al. 2000, Elsdon \& Gillanders 2003b). These studies consistently show

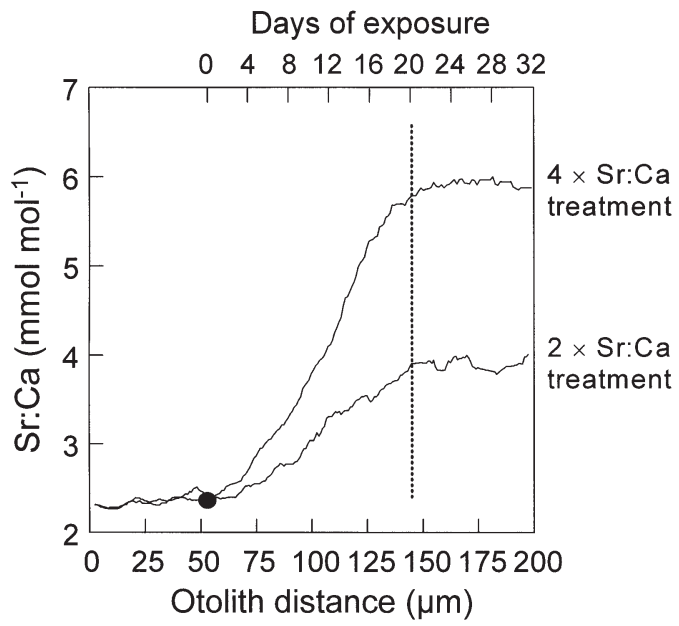

Fig. 5. Acanthopagrus butcheri. Sr:Ca concentrations in fish otoliths for 1 representative fish each from the $2 \times$ and $4 \times$ enhanced elemental treatments, over $32 \mathrm{~d}$. Individual transects are plotted such that the starting points of the treatments match up $(\bullet)$. Dotted line represents the saturation of $\mathrm{Sr}: \mathrm{Ca}$ in otoliths, after which very little change in otolith $\mathrm{Sr}: \mathrm{Ca}$ concentration occurred 
Table 2. Acanthopagrus butcheri. Analysis of variance comparing the (a) maximum Sr:Ca concentration (height), (b) time period of uptake (distance), (c) rate of uptake (slope) and (d) total concentration of Sr:Ca in otoliths of fish (area), for each treatment (Conc.: concentration). Cochran's test was used to test homogeneity of variance; tests that were significant (height, distance, slope and area) were $\ln (x+1)$-transformed after which homogeneity was achieved in all cases

\begin{tabular}{|c|c|c|c|c|c|}
\hline & Source of variation & df & MS & $F$ & $\mathrm{p}$ \\
\hline \multirow{5}{*}{ (a) Height } & Concentration & 1 & 7.9736 & 273.42 & 0.0000 \\
\hline & Time & 4 & 4.7577 & 163.14 & 0.0000 \\
\hline & Tank (Conc. $\times$ Time) & 10 & 0.0292 & 0.98 & 0.4679 \\
\hline & Conc. $\times$ Time & 4 & 0.6502 & 22.30 & 0.0001 \\
\hline & Residual & 100 & 0.0298 & & \\
\hline \multirow[t]{5}{*}{ (b) Distance } & ce Concentration & 1 & 0.7964 & 15.21 & 0.0030 \\
\hline & Time & 4 & 5.6585 & 108.06 & 0.0000 \\
\hline & Tank (Conc. $\times$ Time) & 10 & 0.0524 & 1.11 & 0.3587 \\
\hline & Conc. $\times$ Time & 4 & 0.1568 & 2.99 & 0.0726 \\
\hline & Residual & 100 & 0.0470 & & \\
\hline \multirow[t]{5}{*}{ (c) Slope } & Concentration & 1 & 0.0185 & 175.90 & 0.0000 \\
\hline & Time & 4 & 0.0060 & 56.96 & 0.0000 \\
\hline & Tank (Conc. $\times$ Time) & 10 & 0.0001 & 0.94 & 0.4999 \\
\hline & Conc. $\times$ Time & 4 & 0.0026 & 24.51 & 0.0000 \\
\hline & Residual & 100 & 0.0001 & & \\
\hline \multirow{5}{*}{ (d) Area } & Concentration & 1 & 5.4693 & 77.06 & 0.0000 \\
\hline & Time & 4 & 9.8572 & 138.88 & 0.0000 \\
\hline & Tank (Conc. $\times$ Time) & 10 & 0.0710 & 0.96 & 0.4794 \\
\hline & Conc. $\times$ Time & 4 & 0.2108 & 2.97 & 0.0740 \\
\hline & Residual & 100 & 0.0736 & & \\
\hline
\end{tabular}

(Snyder et al. 1992, Ennevor \& Beames 1993, Brown \& Harris 1995, Pollard et al. 1999), analysed structures using solution-based techniques. In these studies, where whole spines and otoliths were dissolved in acid, the resulting concentration is a signal incorporating experimental and nonexperimental periods. Despite the use of solution analysis, Pollard et al. (1999) did detect a significant interactive effect of concentration and exposure time on $\mathrm{Sr}$ concentration in snapper Pagrus auratus spines; this interaction was identical to the interaction we found in the current experiment ( $P$. auratus is a closely related species to black bream $A$. butcheri). Consistency between experiments in both direction and the interaction of effects indicates that exposure time is an important factor worthy of investigation.

The relationship between otolith Sr:Ca and exposure time indicates that elemental uptake into otoliths is not immediate. The lag effect of elemental

that an increase in ambient concentration results in a significant increase in Sr concentration within calcified structures. For fish, this result is consistent between freshwater (see Mugiya et al. 1991) and saltwater species (see Bath et al. 2000). Comparisons of data from the literature with the results of the current experiment are difficult, given that different sampling techniques can affect the detected concentrations of elements when organisms, such as fish, have been reared for short periods of time (Elsdon \& Gillanders 2003a). Consistency in the direction of effects between the results of the current experiment and those found in the literature is particularly important for interpreting concentrations of elements in otoliths, given that the current experiment is among the first to examine fish otoliths from experimental treatments by transect analysis using laser ablation ICP-MS.

Manipulating exposure times adds an additional degree of complexity to interpreting the effect of ambient $\mathrm{Sr}$ :Ca on otolith $\mathrm{Sr}$ :Ca. Interactions between concentration and time in the current experiment, for height (maximum concentration) and area (total concentration), were such that $\mathrm{Sr}$ :Ca was incorporated into otoliths more rapidly and at greater concentrations when fish were exposed to $4 \times$ ambient $\mathrm{Sr}: \mathrm{Ca}$, compared to at $2 \times$ ambient $\mathrm{Sr}: \mathrm{Ca}$. Previous studies assessing the influence of exposure time to enhanced concentrations of elements in fish spines and otoliths uptake into otoliths has implications for the interpretations of past experiments in which fish were reared for short periods of time. Experiments in which fish were

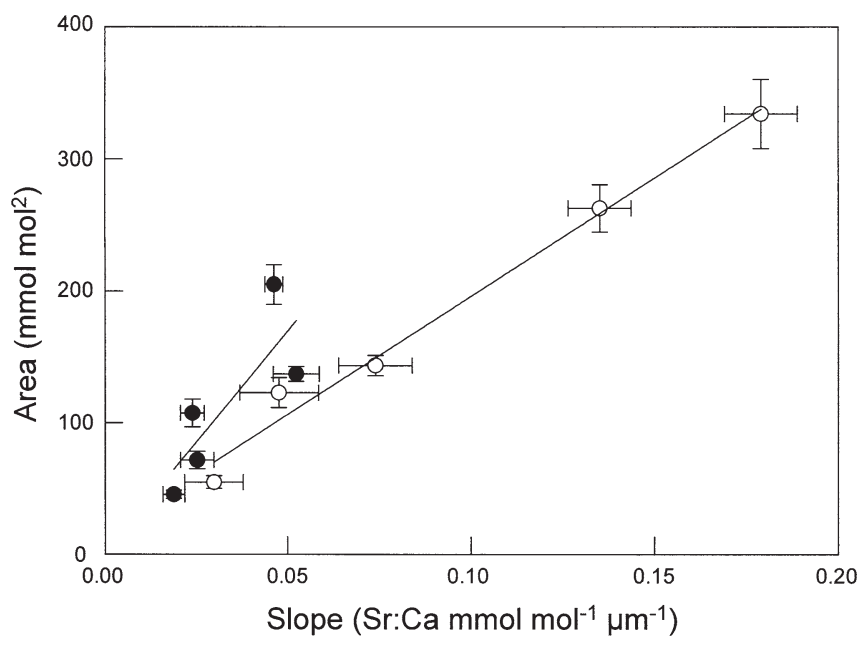

Fig. 6. Acanthopagrus butcheri. Plot of area (total Sr:Ca concentration) versus slope (rate of Sr:Ca uptake) in otoliths of black bream reared under enhanced concentrations of $\mathrm{Sr}: \mathrm{Ca}$ $(2 \times$ and $4 \times)$ for increasing time periods $(2,4,8,16$ and $32 \mathrm{~d})$. Black circles represent treatment tanks of $2 \times$ ambient $\mathrm{Sr}: \mathrm{Ca}$, and clear circles represent treatment tanks of $4 \times$ ambient $\mathrm{Sr}$ :Ca. Bars represent the mean $\pm \mathrm{SE}$ of the mean of each treatment. The value of ' 0 ' represents control fish that were reared at $1 \times$ (ambient) $\mathrm{Sr}$ :Ca concentration 
reared for < 20 d (see Elsdon \& Gillanders 2003a for a review) would provide underestimates of otolith $\mathrm{Sr}$ concentrations (Secor et al. 1995). Likewise, analyses that incorporate otolith material laid down in the first $20 \mathrm{~d}$ of exposure will underestimate otolith Sr concentration (Elsdon \& Gillanders 2003b); this includes solution-based analyses (Bath et al. 2000, Martin et al. 2004). An example of underestimation of $\mathrm{Sr}$ is given by Elsdon \& Gillanders (2003a), who showed that otolith elemental concentrations from fish reared for $32 \mathrm{~d}$ under constant conditions can be underestimated if analysed using large portions of otolith material (100 $\mu \mathrm{m}$ spot analysis on outside edge) versus smaller portions of otolith (30 $\mu \mathrm{m}$ spot analysis). The differences in elemental concentrations between 100 and $30 \mu \mathrm{m}$ spot analyses are clear although both techniques sampled otolith material that was laid down under constant experimental conditions. Therefore, short rearing periods and different sampling techniques can lead to lower chemical concentrations being detected in otoliths. As a result, derived partition coefficients do not represent steady-state conditions. The effect of exposure time on elemental uptake into otoliths may explain differences in the partition coefficient between sampling techniques and between experiments (e.g. Bath et al. 2000, Elsdon \& Gillanders 2003b, Martin et al. 2004). We believe that more work is needed in this area; until such time generalisation of the results of experiments will remain difficult.

When fish in the current experiment were exposed to enhanced elemental concentrations for $32 \mathrm{~d}$, a distinct plateau of $\mathrm{Sr}$ :Ca concentration was observed to occur after approximately $20 \mathrm{~d}$ of exposure, suggesting that Sr:Ca became saturated in otoliths. This result is novel for fish otoliths. Although other fields of research, such as coral calcification, have suggested that saturation of $\mathrm{Sr}$ :Ca in skeletal material does not occur (see Ferris-Pagès et al. 2002), we have clearly shown that elemental saturation is reached in otoliths. Given the difference between coral and otolith elemental concentrations (Campana \& Thorrold 2001), the discrepancies in partition coefficients (Martin et al. 2004) and the results we present here on elemental uptake, we believe that comparisons of effects among different calcified structures are not justified. Clearly, different models of calcification and elemental incorporation occur between fish and invertebrates; therefore, the applications and results from one field may not transcend to the other. Importantly, we have identified a lag effect of elemental uptake using transect analyses across fish otoliths, and have identified a minimum period of exposure time required for otoliths to fully incorporate $\mathrm{Sr}$ :Ca from the ambient environment. These data should allow for the residency time of fish in different environments to be calculated.

\section{Applications to environmental reconstructions}

Reconstructing environmental histories of fish is reliant on predictable effects of environmental variables on the elements in calcified structures. Individual measures of elemental uptake and incorporation into otoliths, when considered independently (from measures such as distance, slope, or area), do not allow for accurate classification of environments inhabited at specific points in time. In the current study, when variables such as the area underneath peaks (total Sr:Ca concentration) and slope (rate of elemental uptake) were combined, greater discrimination was found between fish exposed for different periods of time to varying ambient Sr:Ca concentrations. Such discrimination would allow differentiation between fish that occupied different habitats for different periods of time. Thus, the results of the current experiment also cast doubt on the usefulness of linear equations that use the effects of only 1 environmental variable (see Elsdon \& Gillanders 2003b for an example) to reconstruct the environmental histories of fish. Questioning the usefulness of linear equations is especially pertinent for fish that can move through environments quickly, without enough time being spent in any single environment to fully incorporate elements.

Questions regarding the influence of growth rates on reconstructions are equally important, if reconstructions bridge several years of fish growth. Where differences in otolith growth occur with fish age (e.g. Jones 2000), interpretations of otolith chemistry would be altered by the amount of otolith precipitated between the annuli. Although attempts could be made to scale results to fish growth, where ontogeny may affect otolith chemistry, this would require additional testing to that done in the current study. Studies that have examined Sr:Ca concentrations across otoliths, where growth rates change (e.g. Limburg 1995), require cautious interpretation with regard to environmental histories. Nevertheless, reconstructions of environmental histories for short periods of constant growth (e.g. Katayama et al. 2000) are less susceptible to errors in interpretation.

\section{Interpreting reconstructions and limitations}

The type and scale of environmental histories derived from otolith chemistry largely depend on the biology of the organism (Elsdon \& Gillanders 2003a). Resident fish, which are either territorial or very confined in movement, can be analysed based solely on the changes in environmental variables surrounding the organism. Interpretation of the environmental histories of resident fish, therefore, requires knowledge of 
the fish's age, its growth rate and the stability of the surrounding environmental variables (e.g. Hatje et al. 2001) to be factored into reconstructions. Reconstructions of the environmental histories of migratory fish are quite complex and require knowledge of several additional factors in order to interpret whether the organism has moved or whether the environment occupied has changed. These factors include: (1) the rate of fish movement, (2) the rate of change of environmental variables and (3) knowledge of how growth rates may change with age and water temperature or with metabolism (see Elsdon \& Gillanders 2003a for a review). Once these factors have been defined, information from the current experiment, such as the area and the slope of peaks along transects, can be used to deduce the amount of time fish have spent in different environments.

The complexity of interpreting environmental histories from otolith chemistry increases when multiple environmental variables influence or interact to affect otolith chemistry (e.g. Elsdon \& Gillanders 2002). The results we present are useful in interpreting the environmental histories of fish based solely on ambient chemistry and the effect of exposure time. However, when temperature and salinity also affect otolith chemistry (Hoff \& Fuiman 1995, Secor et al. 1995, Bath et al. 2000, Yamashita et al. 2000, Elsdon \& Gillanders 2002, Martin et al. 2004), the delayed effect of these on elemental incorporation remain unknown. Therefore, our results are best suited for environmental reconstructions in habitats where temperature and salinity are stable, such as in estuaries with similar temperatures to the surrounding coastal environment. In situations where this occurs, we suggest that combining multiple variables of Sr uptake and incorporation into otoliths, such as the area and slope of transects, would allow more accurate discrimination of environmental histories.

Acknowledgements. This research was supported by an APA to T.S.E. and an ARC QEII Fellowship to B.M.G. Funding was provided from an ARC large grant to B.M.G. We are grateful to Andrew Irving and Alexandra Bloomfield for assistance in the rearing of juvenile fish and in water collection. We thank the SARDI Aquatic Sciences for a fresh supply of seawater. We thank Steve Campana for constructive comments on the results and Christina Ferrier-Pagès, Gretchen Bath Martin and Heather Patterson for insightful discussions regarding uptake and incorporation of Sr. Three anonymous reviewers helped improve the final version of this manuscript.

\section{LITERATURE CITED}

Alibert C, McCulloch MT (1997) Strontium/calcium ratios in modern Porites corals from the Great Barrier Reef as a proxy for sea surface temperature: calibration of the thermometer and monitoring of ENSO. Paleoceanography 12: $345-363$
Bath GE, Thorrold SR, Jones CM, Campana SE, McLaren JW, Lam JWH (2000) Strontium and barium uptake in aragonitic otoliths of marine fish. Geochim Cosmochim Acta 64: $1705-1714$

Brown CL, Luoma SN (1995) Use of the euryhaline bivalve Potamocorbula amurensis as a biosentinel species to assess trace metal contamination in San Francisco Bay. Mar Ecol Prog Ser 124:129-142

Brown P, Harris JH (1995) Strontium batch-marking of golden perch (Macquaria ambigua Richardson) and trout cod (Maccullochella macquariensis) (Cuvier). In: Secor DH, Dean JM, Campana SE (eds) Recent developments in fish otolith research. University of South Carolina Press, Columbia, SC, p 693-701

Campana SE (1999) Chemistry and composition of fish otoliths: pathways, mechanisms and applications. Mar Ecol Prog Ser 188:263-297

Campana SE, Thorrold SR (2001) Otoliths, increments, and elements: keys to a comprehensive understanding of fish populations? Can J Fish Aquat Sci 58:30-38

Elsdon TS, Gillanders BM (2002) Interactive effects of temperature and salinity on otolith chemistry: challenges for determining environmental histories of fish. Can J Fish Aquat Sci 59:1796-1808

Elsdon TS, Gillanders BM (2003a) Reconstructing migratory patterns of fish based on environmental influences on otolith chemistry. Rev Fish Biol Fishes 13:219-235

Elsdon TS, Gillanders BM (2003b) Relationship between water and otolith elemental concentrations in juvenile black bream Acanthopagrus butcheri. Mar Ecol Prog Ser 260:263-272

Ennevor BC, Beames RM (1993) Use of lanthanide elements to mass mark juvenile salmonids. Can J Fish Aquat Sci 50: 1039-1044

Fallon SJ, McCulloch MT, van Woesik R, Sinclair DJ (1999) Corals at their latitudinal limits: laser ablation trace element systematics in Porites from Shirigai Bay, Japan. Earth Planet Sci Lett 172:221-238

Fallon S, White J, McCulloch M (2002) Porites corals as recorders of mining and environmental impacts: Misima Island, Papua New Guinea. Geochim Cosmochim Acta 66: $45-62$

Ferris-Pagès C, Boisson F, Allemand D, Tambutté E (2002) Kinetics of strontium uptake in the scleractinian coral Stylophora pistillata. Mar Ecol Prog Ser 245:93-100

Hatje V, Rae K, Birch GF (2001) Trace metal and total suspended solids concentrations in freshwater: the importance of small-scale temporal variation. J Environ Monit 3: 251-256

Hoff GR, Fuiman LA (1995) Environmentally induced variation in elemental composition of red drum (Sciaenops ocellatus) otoliths. Bull Mar Sci 56:578-591

Ikeda Y, Arai N, Kidokoro H, Sakamoto W (2003) Strontium:calcium ratios in statoliths of Japanese common squid Todarodes pacificus (Cephalopoda: Immastrephidae) as indicators of migratory behaviour. Mar Ecol Prog Ser 251:169-179

Jones CM (2000) Fitting growth curves to retrospective sizeat-age data. Fish Res (Amst) 46:123-129

Kafemann R, Adlerstein S, Neukamm R (2000) Variation in otolith strontium and calcium ratios as an indicator of lifehistory strategies of freshwater fish species within a brackish water system. Fish Res (Amst) 46:313-325

Katayama S, Radtke RL, Omori M, Shafer DJ (2000) Coexistence of anadromous and resident life history styles of pond smelt, Hypomesus nipponensis, in Lake Ogawara, Japan, as determined by analyses of otolith structure and 
strontium:calcium ratios. Environ Biol Fishes 58:195-201

Lahaye Y, Lambert D, Walters S (1997) Ultraviolet laser sampling and high resolution inductively coupled plasmamass spectrometry of NIST and BCR-2G glass reference materials. Geostand Newsl 21:205-214

Lea DW, Spero HJ (1992) Experimental determination of barium uptake in shells of the planktonic foraminifera Orbulina universa at $22^{\circ} \mathrm{C}$. Geochim Cosmochim Acta 56: 2673-2680

Lea DW, Spero HJ (1994) Assessing the reliability of paleochemical tracers: barium uptake in the shells of planktonic foraminifera. Paleoceanography 9:445-452

Limburg KE (1995) Otolith strontium traces environmental history of subyearling American shad Alosa sapidissima. Mar Ecol Prog Ser 119:25-35

Ludden JN, Feng R, Gauthier G, Stix J, Shi L, Francis D, Machado N, Wu G (1995) Applications of LAM-ICP-MS analysis to minerals. Can Mineral 33:419-434

Martin GB, Thorrold SR, Jones CM (2004) Temperature and salinity effects on strontium incorporation in otoliths of larval spot (Leiostomus xanthurus). Can J Fish Aquat Sci 61: $34-42$

Milton DA, Chenery SR (2001) Sources and uptake of trace metals in otoliths of juvenile barramundi (Lates calcarifer). J Exp Mar Biol Ecol 264:47-65

Mugiya Y, Hakomori T, Hatsutori K (1991) Trace metal incorporation into otoliths and scales in the goldfish, Carassius auratus. Comp Biochem Physiol C 99:327-331

Pollard M, Kingsford M, Battaglene S (1999) Chemical marking of juvenile snapper, Pagrus auratus (Sparidae), by incorporation of strontium into dorsal spines. Fish Bull 97: 118-131

Rosenthal Y, Boyle EA, Slowey N (1997) Temperature control on the incorporation of manganese, strontium, florine and cadmium into benthic foraminiferal shells from Little Bahama Bank: prospects for thermocline paleoceanography. Geochim Cosmochim Acta 61:3633-3643

Schroder S, Knudsen C, Volk E (1995) Marking salmon fry with strontium chloride solutions. Can J Fish Aquat Sci 52: 1141-1149

Secor DH, Henderson-Arzapalo A, Piccoli PM (1995) Can

Editorial responsibility: Otto Kinne (Editor-in-Chief), Oldendorf/Luhe, Germany otolith microchemistry chart patterns of migration and habitat utilization in anadromous fishes? J Exp Mar Biol Ecol 192:15-33

Secor DH, Rooker JR, Zlokovitz E, Zdanowicz VS (2001) Identification of riverine, estuarine, and coastal contingents of Hudson River striped bass based upon otolith elemental fingerprints. Mar Ecol Prog Ser 211:245-253

Shen CC, Lee T, Chemn CY, Wang C-H, Dai CF, Li LA (1996) The calibration of $\mathrm{D}[\mathrm{Sr} / \mathrm{Ca}]$ versus sea surface temperature relationship for Porites corals. Geochim Cosmochim Acta 60:3849-3858

Shen KN, Lee YC, Tzeng WN (1998) Use of otolith microchemistry to investigate the life history pattern of gobies in a Taiwanese stream. Zool Stud 37:322-329

Sinclair DJ, Kinsley LPJ, McCulloch MT (1998) High resolution analysis of trace elements in corals by laser ablation ICP-MS. Geochim Cosmochim Acta 62:1889-1901

Snyder RJ, McKeown BA, Colbow K, Brown R (1992) Use of dissolved strontium in scale marking of juvenile salmonids: effect of concentration and exposure time. Can J Fish Aquat Sci 49:780-782

Tzeng WN, Severin KP, Wickström H (1997) Use of otolith microchemistry to investigate the environmental history of European eel Anguilla anguilla. Mar Ecol Prog Ser 149: 73-81

Tzeng WN, Shiao JC, Iizuka Y (2002) Use of otolith Sr:Ca ratios to study the riverine migration behaviours of Japanese eel Anguilla japonica. Mar Ecol Prog Ser 245:213-221

Wells BK, Bath GE, Thorrold SR, Jones CM (2000) Incorporation of strontium, cadmium, and barium in juvenile spot (Leiostomus xanthurus) scales reflects water chemistry. Can J Fish Aquat Sci 57:2122-2129

Yamashita Y, Otake T, Yamada H (2000) Relative contributions from exposed inshore and estuarine nursery grounds to the recruitment of stone flounder, Platichthys bicoloratus, estimated using otolith Sr:Ca ratios. Fish Oceanogr 9:316-327

Zacherl DC, Manriques PH, Paradis G, Day RW, Castilla JC, Warner RR, Lea DW, Gaines SD (2003) Trace elemental fingerprinting of gastropod statoliths to study larval dispersal trajectories. Mar Ecol Prog Ser 248:297-303

Submitted: February 2, 2004; Accepted: August 24, 2004

Proofs received from author(s): January 3, 2005 